\title{
In utero exposure to a low concentration of diesel exhaust affects spontaneous locomotor activity and monoaminergic system in male mice
}

\author{
Tomoharu Suzuki ${ }^{1,5}$, Shigeru Oshio ${ }^{1,2,4}$, Mari Iwata ${ }^{1}$, Hisayo Saburi ${ }^{1}$, Takashi Odagiri', Tadashi Udagawa ${ }^{3}$,
} Isamu Sugawara ${ }^{3,4}$, Masakazu Umezawa', Ken Takeda ${ }^{1, *^{*}}$

\begin{abstract}
Background: Epidemiological studies have suggested that suspended particulate matter (SPM) causes detrimental health effects such as respiratory and cardiovascular diseases, and that diesel exhaust particles from automobiles is a major contributor to SPM. It has been reported that neonatal and adult exposure to diesel exhaust damages the central nervous system (CNS) and induces behavioral alteration. Recently, we have focused on the effects of prenatal exposure to diesel exhaust on the CNS. In this study, we examined the effects of prenatal exposure to low concentration of diesel exhaust on behaviour and the monoaminergic neuron system. Spontaneous locomotor activity (SLA) and monoamine levels in the CNS were assessed.
\end{abstract}

Methods: Mice were exposed prenatally to a low concentration of diesel exhaust $\left(171 \mu \mathrm{g} \mathrm{DEP} / \mathrm{m}^{3}\right)$ for 8 hours/day on gestational days 2-16. SLA was assessed for 3 days in 4-week-old mice by analysis of the release of temperature-associated infrared rays. At 5 weeks of age, the mice were sacrificed and the brains were used for analysis by high-performance liquid chromatography (HPLC).

Results and Discussion: Mice exposed to a low concentration of diesel exhaust showed decreased SLA in the first 60 minutes of exposure. Over the entire test period, the mice exposed prenatally to diesel exhaust showed decreased daily SLA compared to that in control mice, and the SLA in each 3 hour period was decreased when the lights were turned on. Neurotransmitter levels, including dopamine and noradrenaline, were increased in the prefrontal cortex (PFC) in the exposure group compared to the control group. The metabolites of dopamine and noradrenaline also increased in the PFC. Neurotransmitter turnover, an index of neuronal activity, of dopamine and noradrenaline was decreased in various regions of the CNS, including the striatum, in the exposure group. The serum corticosterone level was not different between groups. The data suggest that decreased SLA in mice exposed prenatally to diesel exhaust is due to facilitated release of dopamine in the PFC.

Conclusions: These results indicate that exposure of mice in utero to a low concentration of diesel exhaust decreases SLA and alters the neurochemical monoamine metabolism of several regions of the brain.

\section{Background}

Several epidemiological studies have shown a positive association between the level of ambient particulate matter (PM) and mortality caused by respiratory and cardiovascular diseases [1,2]. Diesel engines produce large amounts of PM, and the health effects of exposure

\footnotetext{
* Correspondence: takedak@rs.noda.tus.ac.jp

'Department of Hygiene Chemistry, Faculty of Pharmaceutical Sciences, Tokyo University of Science, 2641 Yamazaki, Noda-city, Chiba 278-8510, Japan
}

C 2010 Suzuki et al; licensee BioMed Central Ltd. This is an Open Access article distributed under the terms of the Creative Commons

to diesel exhaust have been studied. According to several reports, diesel exhaust and diesel exhaust particles (DEPs), the particulate components of diesel exhaust, can affect the central nervous system (CNS). An epidemiological study showed a group of railroad workers exposed to diesel exhaust had impairment of neurobehaviour [3]. Subsequent studies showed that severe air pollution is associated with brain inflammation, Alzheimer's-like pathology [4-6], disruption of blood-brain barrier [6] and cognitive deficit $[7,8]$. The exposure of 
human volunteers to ambient levels of DEPs showed abnormal electrical signals of their frontal cortex, the important area for higher brain functions [9]. Animal models have been used to clarify the mechanisms underlying the effects of diesel exhaust exposure. The molecular toxicity of diesel exhaust is suggested to include oxidative stress-mediated inflammation, which is considered to be central to both pulmonary and systemic adverse health effects $[10,11]$. It was reported that nano-sized DEPs selectively damage cultured dopaminergic neurons by oxidative insult [12] and intracranial microinjection of fractionated diesel exhaust in rat hippocampus and striatum induces tissue damage in these regions [13]. Furthermore, in a recent study, DEPs induced oxidative stress and increased NF- $\kappa \mathrm{B}$ at the blood-brain barrier of mice [14]. Another study showed that intranasal administration of nano-sized carbon black particles modulated the increase of expression of inflammatory cytokine mRNA, such as interleukin- $1 \beta$, and the levels of amino acid neurotransmitters, such as glutamate and glycine, in the mice olfactory bulb induced by lipoteichoic acid [15]. Regarding the effects of prenatal exposure to diesel exhaust $(0.3-3.0 \mathrm{mg}$ $\left.\mathrm{DEP} / \mathrm{m}^{3}\right)$, numerous caspase-3-positive cells were found in the cerebral cortex and hippocampus of newborn mice [16]. A subsequent study showed that prenatal exposure to diesel exhaust $\left(1.0 \mathrm{mg} \mathrm{DEP} / \mathrm{m}^{3}\right)$ decreased the dopamine turnover, an index of dopamine neuronal activity, in the striatum [17]. However, there are no data to show the effects of prenatal exposure to low concentration of diesel exhaust on the CNS. The present study showed alteration of spontaneous locomotor activity (SLA) and monoamine levels in the CNS of mice following in utero exposure to a low concentration of diesel exhaust $\left(0.171 \mathrm{mg} \mathrm{DEP} / \mathrm{m}^{3}\right)$ that corresponds to 1.71 fold of the Japanese environmental quality standard of daily averaged level of suspended particulate matter (SPM).

\section{Methods}

\section{Animals}

Twenty-six pregnant ICR mice were purchased from Japan SLC Inc. (Shizuoka, Japan) and housed under controlled conditions with 12 hours light/12 hours dark cycle and ad libitum access to food and water. They were divided into two groups: diesel exhaust exposure group $(n=12)$ and control group $(n=14)$. The mice of the exposure group were exposed to diesel exhaust for 8 hours/day (9:00 - 17:00 h.), for 5 days per week (Monday-Friday) in an inhalation chamber at the Research Institute of Tuberculosis (Japan Anti-Tuberculosis Association, Tokyo, Japan) from gestational days (GD) 2 16. After the exposure period, mothers and pups were maintained in a clean room. Pregnant mice delivered their pups on GD 19. The number and the sex ratio of pups in the exposure group and the control group were 114 (male:female $=75: 39)$ and 161 (75:86), respectively. On postnatal day (PND) 4, the number of pups per litter was adjusted randomly to ten. In each group, pups were weaned on PND 21, after which male mice were transported to Tokyo University of Science (Chiba, Japan). Mice were transported carefully to minimize stress factors by Sankyo Labo Service Co., Inc. (Tokyo, Japan) and Tokyo Laboratory Animals Science Co., Ltd. (Tokyo, Japan). All experimental animals were handled in accordance with institutional and national guidelines for the care and use of laboratory animals.

\section{Exposure to diesel exhaust}

A 2369 cc diesel engine (Isuzu Motors Ltd., Tokyo, Japan) was operated at a speed of $1050 \mathrm{rpm}$ and at $80 \%$ load with a commercial oil. The exhaust was introduced into a stainless steel dilution tunnel $(450 \mathrm{~mm}$ diameter $\times$ $6250 \mathrm{~mm}$ ), where the exhaust was mixed with clean air, and average concentrations of exhaust constituents were maintained at $1.06 \times 10^{4}$ suspended particles $/ \mathrm{cm}^{3}$ $\left(171 \mu \mathrm{g} / \mathrm{m}^{3}\right), 1.25 \mathrm{ppm}$ for carbon monoxide (CO), 0.04 $\mathrm{ppm}$ for nitrogen dioxide $\left(\mathrm{NO}_{2}\right)$, and less than $0.01 \mathrm{ppm}$ for sulfur dioxide $\left(\mathrm{SO}_{2}\right)$.

\section{Behavioural analysis}

The SLA of each mouse was measured in a transparent acrylic cage $(20 \mathrm{~cm} \times 31 \mathrm{~cm} \times 13 \mathrm{~cm})$ with an activity monitor with an infrared ray sensor (NS-AS01; Neuroscience Inc., Tokyo, Japan). The analysis was done when the mice were 4 weeks old ( $n=10$ /group). Movement was measured according to the release of temperature-associated infrared rays. SLA counts were collected at $10 \mathrm{~min}$ intervals for 3 days. Data were analyzed automatically with a computerized system (multidigital 32port counter system; Neuroscience Inc.). The analysis was conducted in "a new environment" and in "a home cage environment", which refers to the first 60 min test period just after moving into a new cage and the subsequent test period each day, respectively. Statistical analysis was done with two-way, repeated-measures analysis of variance (ANOVA), in which the variables were diesel exhaust exposure and time, followed by post hoc Student's $t$-test. The level of statistical significance was set at $P<0.05$.

\section{Sampling procedure}

Following the behavioural test, brain and trunk blood were obtained from the animals (5 weeks of age). The body weight of the animals was $28.56-37.51 \mathrm{~g}$ and there was no significant difference in body weight between the exposure group $(32.7 \pm 2.4 \mathrm{~g})$ and the control group $(32.9 \pm 2.0 \mathrm{~g})$. The brain was dissected into 
six regions, immediately frozen in liquid nitrogen, and stored at $-80^{\circ} \mathrm{C}$. Serum was separated in a gel barrier capillary blood collection tube (Capiject T-MG; Terumo Medical Corp., Elkton, MD) followed by centrifugation at $2200 \mathrm{~g}$ at $4{ }^{\circ} \mathrm{C}$ for $15 \mathrm{~min}$ and stored at $-80^{\circ} \mathrm{C}$ until analysis.

\section{Brain dissection}

Brain dissection was done according to the modified method of Heffner et al. [18] and was based on the atlas described by Paxinos and Franklin [19]. The following four regions were dissected from frozen forebrain and midbrain coronal sections on a silicon plate chilled with dry ice: prefrontal cortex (PFC; containing cingulated cortex and motor cortex areas 1 and 2); striatum (dorsal); hippocampus (caudal) and midbrain (containing ventral tegmental area and substantia nigra). Determination of monoamine levels was done in PFC, striatum, hippocampus, midbrain, cerebellum, and brainstem.

\section{Preparation of homogenates}

Frozen brain tissues was homogenized in ice-cold $0.2 \mathrm{M}$ perchloric acid (Nacalai Tesque Inc., Kyoto, Japan) containing $100 \mu \mathrm{M} \mathrm{Na} \mathrm{Na}_{2}$-EDTA (Dojinto Laboratories, Kumamoto, Japan) and $1 \mathrm{ng} / \mathrm{mL}$ isoproterenol as an internal standard (Sigma-Aldrich Co., St. Louis, MO). The homogenates were kept on ice for $30 \mathrm{~min}$ and centrifuged at $20,000 \mathrm{~g}$ at $0^{\circ} \mathrm{C}$ for $15 \mathrm{~min}$. The supernatant was mixed with $1 \mathrm{M}$ sodium acetate to adjust the $\mathrm{pH}$ to 3.0 (Kanto Chemical Co., Inc., Tokyo, Japan) and were frozen immediately in liquid nitrogen and stored at $-80^{\circ} \mathrm{C}$. The precipitate was used for the protein assay.

\section{High-performance liquid chromatography (HPLC)}

Each group contained samples from 10 mice. A $10 \mathrm{~mL}$ sample of the final supernatant was injected with a microsyringe (702SNR; Hamilton Co., Reno, NV) into an HPLC system equipped with an electrochemical detector (HTEC-500MAB; Eicom Co., Kyoto, Japan). The standard solution contained the monoamines dopamine and noradrenaline and their metabolites. The dopamine metabolites were 3-methoxytyramine hydrochloride (3-MT), 3,4-dihydroxyphenylacetic acid (DOPAC) and homovanillic acid (HVA). The noradrenaline metabolites were normetanephrine hydrochloride (NM) and 4-hydroxy-3-methoxyphenylglycol hemipiperazinium (MHPG). Standards dopamine, HVA, 3-MT, NM and MHPG were obtained from Sigma-Aldrich. Standards noradrenaline and DOPAC were obtained from Nacalai Tesque and Wako Pure Chemical Industries, Ltd. (Osaka, Japan), respectively. Separation of monoamines and their metabolites was done by passage through a C18 reverse-phase column (Eicompak SC5ODS; $3.0 \mathrm{~mm} \times 150 \mathrm{~mm}$; Eicom), maintained at $25^{\circ} \mathrm{C}$ and connected to an electrochemical detector (EPC-500, Eicom). The mobile phase was $0.1 \mathrm{M}$ acetic acid/citric acid buffer ( $\mathrm{pH}$ 3.5) containing $\mathrm{Na}_{2}$-EDTA $(5 \mathrm{mg} / \mathrm{L})$, octanesulfonic acid (190 mg/L; Nacalai Tesque), and methanol (15\% (v/v); Kanto Chemical Co., Inc.). The flow rate was maintained at $0.5 \mathrm{~mL} / \mathrm{min}$ for $35 \mathrm{~min}$. Data were collected and analysed with the PowerChrom 280 System (eDAQ Pty Ltd., New South Wales, Australia). To determine the protein concentration, pellets were dissolved in $100 \mathrm{mM}$ Tris- $\mathrm{HCl}$ for protein determination by a high-sensitivity version of the Bradford method with a commercial reagent (ADV-01; Cytoskeleton Inc., Denver, $\mathrm{CO}$ ), and measurements were done according to the manufacturer's protocol. The absorbance at $595 \mathrm{~nm}$ was measured with a 96-well microplate reader (model 550; Bio-Rad Laboratories Inc., Hercules, CA), and protein concentration was calculated from a standard curve generated with bovine $\gamma$-globulin (Pre-Diluted Protein Assay Standards: Bovine Gamma Globulin Set; Thermo Fisher Scientific Inc., Rockford, IL). Concentrations of monoamines and their metabolites are expressed as $\mathrm{pg} \mathrm{mg}^{-1}$ of protein, and the catabolism rate is expressed as the ratio of metabolite to monoamine (e.g. HVA/dopamine). Indices were calculated from individual tissue samples. Statistical analysis was done with the Mann Whitney $U$-test. The level of statistical significance was set at $P<0.05$.

\section{Measurement of serum corticosterone}

The concentration of corticosterone in serum was determined with a Correlate-EIA Corticosterone Enzyme Immunoassay Kit (Assay Designs Inc., Ann Arbor, MI).

\section{Results}

\section{Spontaneous locomotor activity (SLA)}

SLA was measured continuously for 3 days. During the first $60 \mathrm{~min}$, a decrease in locomotor activity in the mice exposed prenatally to diesel exhaust was found by two-way, repeated-measures ANOVA (Figure 1A). A decrease in daily locomotor activity over the entire testing period was also found (Figure 1B). SLA in each 3 hour period was also altered in the exposure group, and post hoc analysis showed that SLA was decreased at some time points (Figure 1C). During the first day, datapoints 3 and 6 showed significantly decreased values. During the second and third days, datapoint 6 showed decreased values.

\section{The levels of monoamine and their metabolites}

The determination of monoamine levels was conducted in six brain regions: PFC, striatum, hippocampus, midbrain, cerebellum and brainstem. In PFC, the levels of dopamine and noradrenaline were increased in the exposure group (Figure 2,3). The dopamine level in 


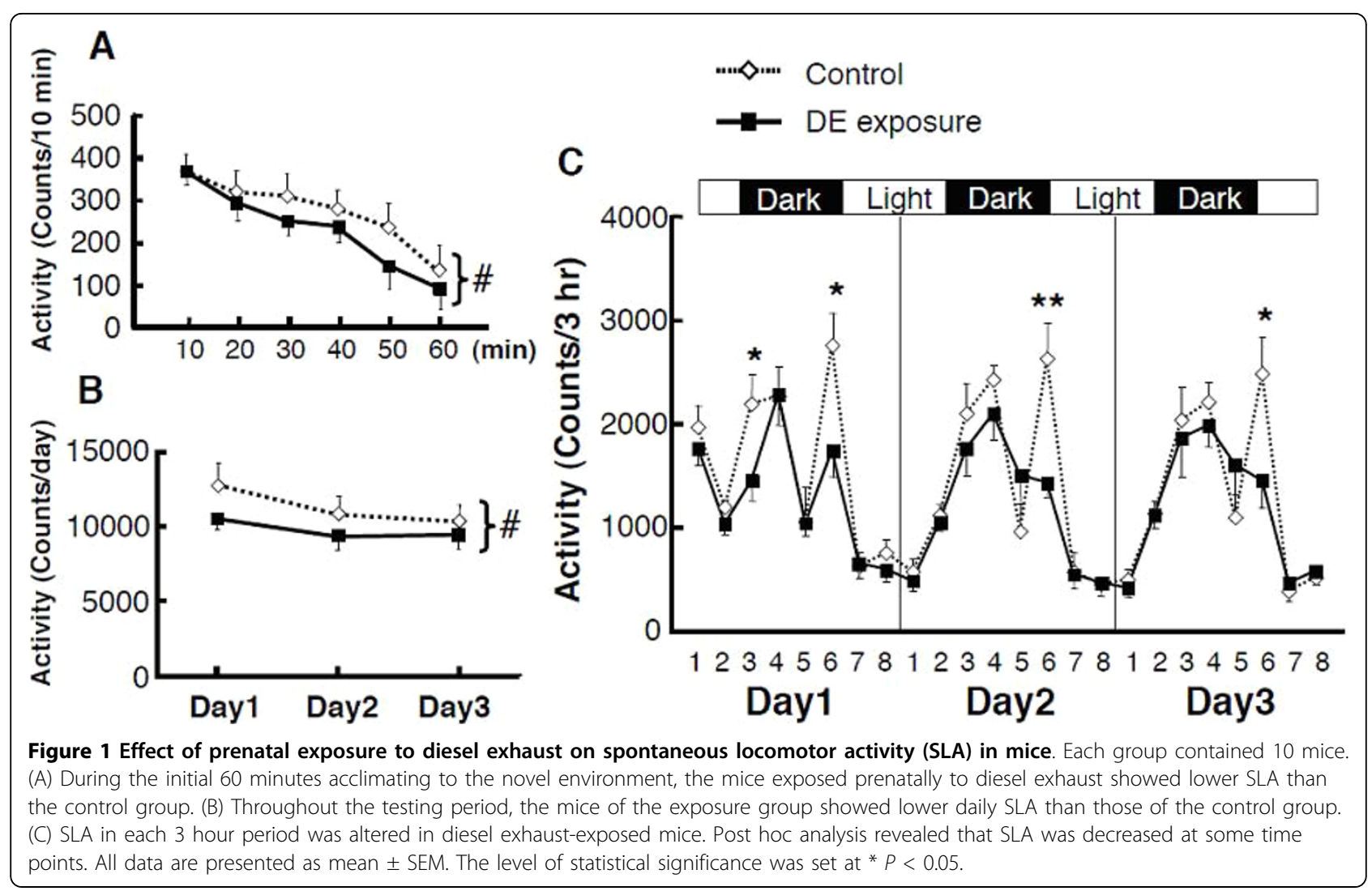

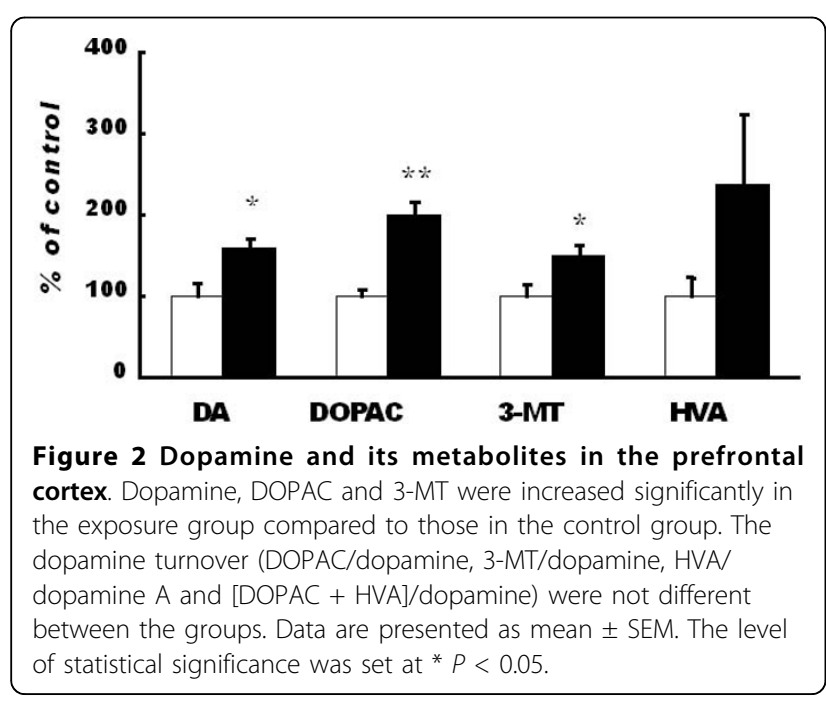

brainstem was decreased (Table 1) but the dopamine and noradrenaline levels were not altered in the other regions. The levels of metabolites of dopamine were increased in the PFC (Figure 2), and the level of HVA was increased in the brainstem (Table 1). These metabolites were decreased in the hippocampus and in the midbrain (Table 1). The levels of metabolites of noradrenaline were increased in the PFC (Figure 3) but were

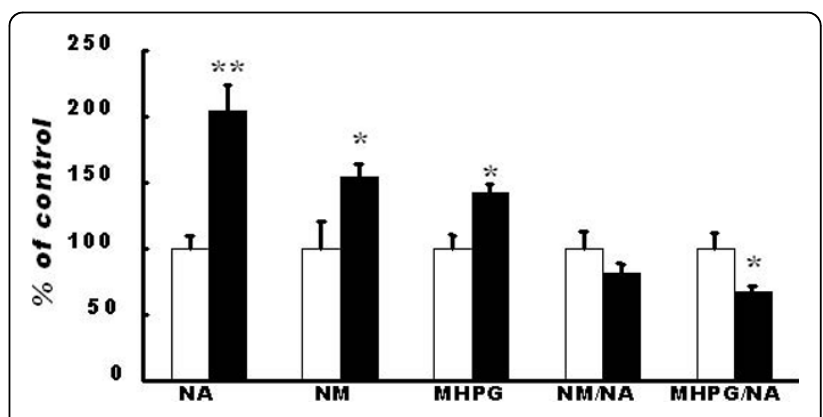

Figure 3 Noradrenaline, its metabolites and turnover in the prefrontal cortex. Noradrenaline, NM and MHPG were increased significantly in the exposure group compared to those in the control group. The noradrenaline turnover (MHPG/noradrenaline) was decreased compared to that in the control group. Data are presented as mean \pm SEM. The level of statistical significance was set at $* P<0.05$.

decreased in the other regions (Table 2). With respect to neurotransmitter turnover, an index of neuronal activity calculated as a ratio of metabolite to transmitter was decreased in some regions of the brain. The turnover of dopamine was decreased in the striatum (Table 3), and that of noradrenaline was decreased in the PFC (Figure 3), striatum, hippocampus, midbrain and cerebellum (Table 4). 
Table 1 Amounts of dopamine and its metabolites (pg $\mathrm{mg}^{-1}$ protein) in each part of the brain.

\begin{tabular}{|c|c|c|c|c|c|}
\hline \multirow[t]{2}{*}{ Brain region } & \multirow[t]{2}{*}{ Group } & \multicolumn{4}{|c|}{ Content (pg mg ${ }^{-1}$ protein) } \\
\hline & & Dopamine & DOPAC & 3-MT & HVA \\
\hline \multirow[t]{2}{*}{ Striatum } & Control & $270999 \pm 30968$ & $20710 \pm 2573$ & $21841 \pm 3409$ & $32479 \pm 3492$ \\
\hline & Exposed & $319714 \pm 14364$ & $20197 \pm 685$ & $22587 \pm 1386$ & $31276 \pm 1956$ \\
\hline \multirow[t]{2}{*}{ Hippocampus } & Control & $1520 \pm 350$ & N.D. & $714 \pm 143$ & $23816 \pm 8826$ \\
\hline & Exposed & $951 \pm 101$ & N.D. & $449 \pm 35$ & $4419 \pm 392^{* *}$ \\
\hline \multirow[t]{2}{*}{ Midbrain } & Control & $4387 \pm 486$ & $2491 \pm 191$ & $773 \pm 71$ & $3864 \pm 225$ \\
\hline & Exposed & $3446 \pm 361$ & $1798 \pm 110^{*}$ & $555 \pm 40^{*}$ & $2847 \pm 238^{*}$ \\
\hline \multirow[t]{2}{*}{ Cerebellum } & Control & $202 \pm 29$ & N.D. & N.D. & $3225 \pm 1152$ \\
\hline & Exposed & $197 \pm 46$ & N.D. & N.D. & $4367 \pm 1343$ \\
\hline \multirow[t]{2}{*}{ Brainstem } & Control & $17959 \pm 646$ & $57513 \pm 2294$ & N.D. & $2952 \pm 252$ \\
\hline & Exposed & $15775 \pm 395^{*}$ & $51445 \pm 2244$ & N.D. & $5382 \pm 517^{* *}$ \\
\hline
\end{tabular}

Data are presented as mean \pm SEM ( $n=10$ per group). The statistical significance is shown as $* P<0.05,{ }^{*} P<0.01 ;$ ND, not detectable. Abbreviations: DOPAC, 3,4-dihydroxyphenylacetic acid; HVA, homovanillic acid; 3-MT, 3-methoxytyramine.

Table 2 Amounts of noradrenaline and its metabolites (pg $\mathrm{mg}^{-1}$ protein) in each part of the brain.

\begin{tabular}{|c|c|c|c|c|}
\hline \multirow[t]{2}{*}{ Brain region } & \multirow[t]{2}{*}{ Group } & \multicolumn{3}{|c|}{ Content (pg $\mathrm{mg}^{-1}$ protein) } \\
\hline & & Noradrenaline & NM & MHPG \\
\hline \multirow[t]{2}{*}{ Striatum } & Control & $1894 \pm 310$ & N.D. & $31671 \pm 2828$ \\
\hline & Exposed & $1983 \pm 278$ & N.D. & $23800 \pm 1064^{*}$ \\
\hline \multirow[t]{2}{*}{ Hippocampus } & Control & $9872 \pm 1149$ & $691 \pm 97$ & $44283 \pm 5051$ \\
\hline & Exposed & $10668 \pm 625$ & $788 \pm 76$ & $30498 \pm 1102^{*}$ \\
\hline \multirow[t]{2}{*}{ Midbrain } & Control & $12498 \pm 954$ & $410 \pm 34$ & $22443 \pm 1466$ \\
\hline & Exposed & $12719 \pm 633$ & $357 \pm 34$ & $14086 \pm 675^{* *}$ \\
\hline \multirow[t]{2}{*}{ Cerebellum } & Control & $4203 \pm 312$ & $615 \pm 60$ & $42898 \pm 3439$ \\
\hline & Exposed & $4174 \pm 262$ & $533 \pm 45$ & $28305 \pm 1730^{*}$ \\
\hline \multirow[t]{2}{*}{ Brainstem } & Control & $457063 \pm 21049$ & $25389 \pm 1775$ & $189692 \pm 11607$ \\
\hline & Exposed & $430512 \pm 18333$ & $20766 \pm 1158^{*}$ & $165359 \pm 16247$ \\
\hline
\end{tabular}

Data are presented as mean \pm SEM ( $n=10$ per group). The statistical significance is shown as ${ }^{*} P<0.05,{ }^{* *} P<0.01 ;$ ND, not detectable. Abbreviations: MHPG, 4hydroxy-3-methoxyphenylglycol; NM, normetanephrine.

\section{Serum corticosterone}

The levels of serum corticosterone were not different between the exposure group and the control group (data not shown).

\section{Discussion}

This is the first study that has demonstrated the effects of in utero exposure to a low concentration of diesel exhaust $\left(0.171 \mathrm{mg} \mathrm{DEP} / \mathrm{m}^{3}\right)$ on locomotor activity and monoamine level in brain tissue. In the present study, we used only male fetuses and pups for analysis because the prevalence of some psychiatric disorders in childhood, such as autism and attention deficit hyperactivity disorder, is higher in men than in women. The results of this study demonstrated that SLA in a new environment and in the home cage environment was decreased and monoaminergic neurochemistry in several regions of the brain was altered in the exposure group. SLA in the home cage environment was particularly decreased when the lights turned on. The alteration of decreased SLA and dopamine turnover in the striatum was similar to a finding in an earlier study that examined the effects of prenatal exposure to a relatively higher concentration of diesel exhaust $\left(1.0 \mathrm{mg} \mathrm{DEP} / \mathrm{m}^{3}\right)$ [17]. The present study showed alteration of the monoamine metabolism in other regions of the CNS, especially the PFC, even by exposure to a lower concentration of diesel exhaust.

It has been reported that diesel exhaust and DEPs contain estrogenic and antiestrogenic compounds and possess endocrine-disrupting activity [20-23]. In the present study, the number of female pups of the exposure group was less than half of that of the control group. It may indicate that embryogenesis of female fetuses was affected by the activity of DEPs. Tsukue et al. [24] examined the effects of exposure to diesel exhaust during the perinatal period on sexual differentiation-related gene expression of the brain. Expression levels of estrogen receptor (ER) $\alpha$ and $E R \beta m R N A$ were increased in 
Table 3 Dopamine turnover in each part of the brain.

\begin{tabular}{llllll}
\hline Brain region & Group & Turnover & & \\
\cline { 2 - 6 } & & DOPAC/dopamine & 3-MT/dopamine & HVA/dopamine & (DOPAC+HVA)/dopamine \\
\hline Striatum & Control & $0.076 \pm 0.004$ & $0.077 \pm 0.004$ & $0.121 \pm 0.004$ & $0.197 \pm 0.006$ \\
\cline { 2 - 6 } & Exposed & $0.064 \pm 0.002^{*}$ & $0.071 \pm 0.003$ & $0.098 \pm 0.004^{*}$ & $0.162 \pm 0.005^{* *}$ \\
\hline Hippocampus & Control & - & $0.60 \pm 0.14$ & $24.66 \pm 12.22$ & - \\
\hline Mxposed & - & $0.51 \pm 0.06$ & $5.15 \pm 0.64$ & - \\
\hline Cerebellum & Control & $0.61 \pm 0.05$ & $0.20 \pm 0.03$ & $0.99 \pm 0.13$ & $1.601 \pm 0.165$ \\
\hline Exprain & Control & - & $0.17 \pm 0.01$ & $0.86 \pm 0.06$ & $1.404 \pm 0.079$ \\
\cline { 2 - 6 } & Exposed & - & - & $17.22 \pm 5.55$ & - \\
\hline
\end{tabular}

Data are presented as mean \pm SEM ( $n=10$ per group). The statistical significance is shown as $* P<0.05,{ }^{*} P<0.01 ;$ ND, not detectable. Abbreviations: DOPAC, 3,4-dihydroxyphenylacetic acid; HVA, homovanillic acid; 3-MT, 3-methoxytyramine.

Table 4 Noradrenaline turnover in each part of the brain.

\begin{tabular}{llll}
\hline Brain region & Group & \multicolumn{2}{l}{ Turnover } \\
\cline { 2 - 4 } & & $\mathbf{N M} /$ noradrenaline & MHPG/noradrenaline \\
\hline Striatum & Control & - & $20.62 \pm 3.14$ \\
\cline { 2 - 4 } & Exposed & - & $14.44 \pm 2.15$ \\
\hline Hippocampus & Control & $0.069 \pm 0.006$ & $4.59 \pm 0.35$ \\
\cline { 2 - 4 } & Exposed & $0.074 \pm 0.007$ & $2.97 \pm 0.24^{* *}$ \\
\hline Midbrain & Control & $0.034 \pm 0.002$ & $1.84 \pm 0.11$ \\
\cline { 2 - 4 } & Exposed & $0.028 \pm 0.003$ & $1.12 \pm 0.06^{* *}$ \\
\hline Cerebellum & Control & $0.145 \pm 0.011$ & $10.82 \pm 1.30$ \\
\cline { 2 - 4 } & Exposed & $0.131 \pm 0.013$ & $6.87 \pm 0.36^{*}$ \\
\hline Brainstem & Control & $0.0568 \pm 0.003$ & $0.415 \pm 0.015$ \\
\cline { 2 - 4 } & Exposed & $0.0487 \pm 0.003$ & $0.380 \pm 0.030$ \\
\hline
\end{tabular}

Data are presented as mean \pm SEM ( $n=10$ per group). The statistical significance is shown as ${ }^{*} P<0.05,{ }^{*} P<0.01$; ND, not detectable. Abbreviations: MHPG, 4-hydroxy-3-methoxyphenylglycol; NM, normetanephrine.

the cerebrum of newborns in the exposure group as well as mRNA for CYP1A1 and $H O-1$. The results indicate that prenatal exposure to diesel exhaust during the critical period of sexual differentiation of the brain may affect endocrine function. Estrogen has many important roles in the brain, including brain development, neuroprotection such as inhibition of apoptosis and synaptogenesis, and functions of the monoaminergic systems [25], the effects of perinatal exposure to diesel exhaust on CNS have been focused on. There is a report that shows serum level of estradiol is increased in male rats exposed to diesel exhaust after birth [26]. However, whether the serum estradiol level is affected by prenatal exposure to diesel exhaust remain unknown. Further investigation is required to clarify the mechanisms of the effects of diesel exhaust exposure on the levels of estradiol and CNS of offspring.
When pregnant mice were exposed to diesel exhaust, cytoplasmic granules of granular perithelial cells contained ultrafine DEP-like particles and the apoptosis of endothelial cells and stenosis of some capillaries were observed [16]. Furthermore, caspase-3 positive cells were observed in the cerebral cortex and in the hippocampus of the newborn [27]. These observations suggest that exposure of pregnant mice to diesel exhaust might carry a risk of cellular atrophy and might affect development of the fetal brain. A review by Herlenius and Lagercrantz [28] indicated that stimulation or insult at critical phases of development of the nervous system could result in long-term changes in organismal structure and function. Perinatal exposure to environmental contaminants, including DEPs, that have hormone-like activity [20-23] and can generate reactive oxygen species [29], might be able to disturb the timetable of expression of neurotransmitters and neuromodulators and their receptors, evoking permanent changes in cellular proliferation and differentiation and in growth, leading to behavioural and neurophysiologic abnormalities. The details of the mechanism how DEPs affect fetus and damage CNS of offspring remain unclear. However, when gold nanoparticle $(1.4-18 \mathrm{~nm})$ is intravenously injected into female rats, inversely size-dependent uptake in the placenta and translocation into the fetus were found [30]. Nanosized fraction of DEPs may majorly contribute to adverse effects on CNS of offspring. The toxicity of DEP for dopamine neurons was shown in an in vitro study [12] and the toxicity for CNS in vivo should be further investigated. The present study showed that daily SLA decreased in the exposure group compared to that in the control group when the mice were put into a new environment. This alteration is similar to that of ovariectomized mice treated with estradiol $[31,32]$, suggesting that it may be caused by 
estrogenic activity of diesel exhaust. The dopamine and noradrenaline systems in the PFC have an important role in the control of locomotor activity. Destruction of mesocortical and dopamine projections in rats results in increased motor activity [33-36], suggesting that one of the roles of dopamine in the PFC is to suppress locomotor activity. In the present study, the data showed that dopamine and its metabolites were increased in the PFC of the exposure group and the basal stress level was not altered by diesel exhaust exposure because the levels of serum corticosterone were not different between groups. The dopamine and noradrenaline systems in the PFC are responsive to various stressors [37,38]. The response of the dopamine system is independent of the pituitaryadrenocortical axis [39]. The cause of decreased SLA in mice exposed prenatally to diesel exhaust may be a transiently facilitated release of dopamine as a result of exposure to novel stimuli rather than alteration of the level of basal stress. Our unpublished data showed that the effects of diesel exhaust exposure on CNS of offspring are reduced by removing the DEPs from the exhaust with a filter. It suggests that particulate component of diesel exhaust contribute to the effects of maternal exposure to diesel exhaust on CNS.

\section{Conclusions}

The exposure to low concentrations of diesel exhaust in utero decreased spontaneous locomotor activity and altered monoaminergic neurochemistry in several regions of the brain in male mice. However, the mechanism connecting the behavioural and neurochemical alterations remains unclear. We cannot rule out an indirect effect of diesel exhaust exposure via the mother's behaviour toward the pups and how this in turn altered SLA and monoamine metabolism in the offspring since this was not investigated. Further investigations are needed to clarify the critical factor for the effects on offspring. Since current observations are done at a particle mass concentration of diesel exhaust close to the environmental quality standard of daily-averaged level of suspended particulate matter (SPM) in Japan, these finding warrant revisiting of present air quality standards for particulate matter.

\footnotetext{
List of abbreviations used

CNS: central nervous system; DEP: diesel exhaust particle; DOPAC: 3,4dihydroxyphenylacetic acid; GD: gestational day; HPLC: High-performance liquid chromatography; HVA: homovanillic acid; MHPG: 4-hydroxy-3methoxyphenylglycol hemipiperazinium; 3-MT: 3-methoxytyramine hydrochloride; NM: normetanephrine hydrochloride; PFC: prefrontal cortex; PM: particulate matter; PND: postnatal day; SLA: spontaneous locomotor activity; SPM: suspended particulate matter.
}

\section{Acknowledgements}

The authors thank Drs. Masao Sugamata and Tomomi Ihara of the Tochigi Institute of Clinical Pathology, De, Seiichi Yoshida of Oita University of
Nursing and Health Sciences, Dr. Naomi Tsukue of Japan Automobile Research Institute and Drs. Tsutomu Suzuki and Minoru Narita of Hoshi University for valuable discussions. The authors also thank Ms. Satomi Abe for technical assistance. This work was supported in part by a grant from Core Research for Evolutional Science and Technology (CREST) of the Japan Science and Technology Agency (JST), a Grant-in-Aid from the Ministry of Education, Culture, Sports, Science and Technology of Japan, and a Grant-inAid from Private University Science Research Upgrade Promotion Business Academic Frontier Project.

\section{Author details}

'Department of Hygiene Chemistry, Faculty of Pharmaceutical Sciences, Tokyo University of Science, 2641 Yamazaki, Noda-city, Chiba 278-8510, Japan. ${ }^{2}$ Department of Hygiene Chemistry, School of Pharmaceutical Sciences, Ohu University, 31-3 Misumido, Tomita-cho, Koriyama-city, Fukishima 963-8611, Japan. ${ }^{3}$ Department of Molecular Pathology, Research Institute of Tuberculosis, 3-1-24 Matsuyama, Kiyose-city, Tokyo 204-8533, Japan. ${ }^{4}$ Core Research for Evolutional Science and Technology (CREST), Japan Science and Technology Agency), 4-1-8 Hon-cho, Kawaguchi-city, Saitama 332-0012, Japan. ${ }^{5}$ School of Medicine and Medical Sciences, University of Tsukuba, 1-1-1 Tennodai, Tsukuba-city, Ibaraki 305-8577, Japan.

\section{Authors' contributions}

$\mathrm{TS}, \mathrm{SO}, \mathrm{MI}, \mathrm{HS}$ and TO were substantially involved in conducting the experiments. TS and MU was involved in data analyses and in drafting the manuscript. TU and IS conducted and controlled the diesel exhaust exposure. $\mathrm{KT}$ is the main project leader and conceived the overall research idea. All authors read and approved the final manuscript.

\section{Competing interests}

The authors declare that they have no competing interests.

Received: 16 November 2009 Accepted: 23 March 2010

Published: 23 March 2010

\section{References}

1. Ostro B, Broadwin R, Green S, Feng WY, Lipsett M: Fine particulate air pollution and mortality in nine California counties: results from CALFINE. Environ Health Perspect 2006, 114:29-33.

2. Pope CA, Burnett RT, Thurston GD, Thun MJ, Calle EE, Krewski D, Godleski JJ: Cardiovascular mortality and long-term exposure to particulate air pollution: epidemiological evidence of general pathophysiological pathways of disease. Circulation 2004, 109:71-77.

3. Kilburn $\mathrm{KH}$ : Effects of diesel exhaust on neurobehavioral and pulmonary functions. Arch Environ Health 2000, 55:11-17.

4. Calderón-Garcidueñas L, Maronpot RR, Torres-Jardon R, Henríquez-Roldán C, Schoonhoven R, Acuña-Ayala H, Villarreal-Calderón A, Nakamura J, Fernando R, Reed W, Azzarelli B, Swenberg JA: DNA damage in nasal and brain tissues of canines exposed to air pollutants is associated with evidence of chronic brain inflammation and neurodegeneration. Toxicol Pathol 2003, 31:524-538.

5. Calderón-Garcidueñas $L$, Reed W, Maronpot RR, Henríquez-Roldán C, Delgado-Chavez R, Calderón-Garcidueñas A, Dragustinovis I, Franco-Lira M, Aragón-Flores M, Solt AC, Altenburg M, Torres-Jardón R, Swenberg JA: Brain inflammation and Alzheimer's-like pathology in individuals exposed to severe air pollution. Toxicol Pathol 2004, 32:650-658.

6. Calderón-Garcidueñas L, Solt AC, Henríquez-Roldán C, Torres-Jardón R, Nuse B, Herritt L, Villarreal-Calderón R, Osnaya N, Stone I, García R, Brooks DM, González-Maciel A, Reynoso-Robles R, Delgado-Chávez R, Reed W: Long-term air pollution exposure is associated with neuroinflammation, an altered innate immune response, disruption of the blood-brain barrier, ultrafine particulate deposition, and accumulation of amyloid beta- 42 and alpha-synuclein in children and young adults. Toxicol Pathol 2008, 36:289-310.

7. Suglia SF, Gryparis A, Wright RO, Schwartz J, Wright RJ: Association of black carbon with cognition among children in a prospective birth cohort study. Am J Epidemiol 2007, 167:280-286.

8. Calderón-Garcidueñas L, Mora-Tiscareño A, Ontiveros E, Gómez-Garza G, Barragán-Mejía G, Broadway J, Chapman S, Valencia-Salazar G, Jewells V, Maronpot RR, Henríquez-Roldán C, Pérez-Guillé B, Torres-Jardón R, Herrit L, Brooks D, Osnaya-Brizuela N, Monroy ME, González-Maciel A, Reynoso- 
Robles R, Villarreal-Calderon R, Solt AC, Engle RW: Air pollution, cognitive deficits and brain abnormalities: a pilot study with children and dogs. Brain Cogn 2008, 68:117-127.

9. Crüts $B$, van Etten L, Törnqvist $H$, Blomberg A, Sandström T, Mills NL, Borm PJ: Exposure to diesel exhaust induces changes in EEG in human volunteers. Part Fibre Toxicol 2008, 5:4.

10. Block ML, Wu X, Pei Z, Li G, Wang T, Qin L, Wilson B, Yang J, Hong JS, Veronesi B: Nanometer size diesel exhaust particles are selectively toxic to dopaminergic neurons: the role of microglia, phagocytosis, and NADPH oxidase. FASEB J 2004, 18:1618-1620.

11. Anderson $H$, Lindqvist $E$, Westerholm $R$, Gragg $K$, Almen J, Oslon L: Neurotoxic effects of fractionated diesel exhausts following microinjections in rat hippocampus and striatum. Environ Res 1998, 76:41-51.

12. Hartz AM, Bauer B, Block ML, Hong JS, Miller DS: Diesel exhaust particles induce oxidative stress, proinflammatory signaling, and P-glycoprotein up-regulation at the blood-brain barrier. FASEB J 2008, 22:2723-2733.

13. Donaldson K, Stone V, Borm PJ, Jimenez LA, Gilmour PS, Schins RP, Knaapen AM, Rahman I, Faux SP, Brown DM, MacNee W: Oxidative stress and calcium signaling in the adverse effects of environmental particles (PM10). Free Radic Biol Med 2003, 34:1369-1382.

14. Donaldson $K$, Tran L, Jimenez LA, Duffin R, Newby DE, Mills N, MacNee W, Stone V: Combustion-derived nanoparticles: a review of their toxicology following inhalation exposure. Part Fibre Toxicol 2005, 2:10.

15. Tin-Tin-Win-Shwe, Mitsushima D, Yamamoto S, Fukushima A, Funabashi T, Kobayashi T, Fujimaki H: Changes in neurotransmitter levels and proinflammatory cytokine mRNA expressions in the mice olfactory bulb following nanoparticle exposure. Toxicol Appl Pharmacol 2008, 226:192-198

16. Sugamata M, Ihara T, Takano H, Oshio S, Takeda K: Maternal diesel exhaust exposure damages newborn murine brains. J Health Sci 2006, 52:82-84.

17. Yokota S, Mizuo K, Moriya N, Oshio S, Sugawara I, Takeda K: Effect of prenatal exposure to diesel exhaust on dopaminergic system in mice. Neurosci Lett 2009, 449:38-41.

18. Heffner TG, Hartman JA, Seiden LS: A rapid method for the regional dissection of the rat brain. Pharmacol Biochem Behav 1980, 13:453-456.

19. Paxinos $G$, Franlin KBJ: The mouse brain in stereotaxic coordinates. Academic Press, 22001.

20. Takeda K, Tsukue N, Yoshida S: Endocrine-disrupting activity of chemicals in diesel exhaust and diesel exhaust particles. Environ Sci 2004, 11:33-45.

21. Kizu R, Okamura K, Toriba A, Mizokami A, Burnstein KL, Klinge CM, Hayakawa K: Antiandrogenic activities of diesel exhaust particle extracts in PC3/AR human prostate carcinoma cells. Toxicol Sci 2003, 76:299-309.

22. Okamura K, Kizu R, Toriba A, Murahashi T, Mizokami A, Burnstein KL, Klinge CM, Hayakawa K: Antiandrogenic activity of extracts of diesel exhaust particles emitted from diesel-engine truck under different engine loads and speeds. Toxicology 2004, 195:243-254.

23. Furuta C, Li C, Taneda S, Suzuki AK, Kamata K, Watanabe G, Taya K: Immunohistological study for estrogenic activities of nitrophenols in diesel exhaust particles. Endocrine 2005, 27:33-36.

24. Tsukue N, Watanabe M, Kumamoto T, Takano H, Takeda K: Perinatal exposure to diesel exhaust affects gene expression in mouse cerebrum. Arch Toxicol 2009, 83:985-1000.

25. McEwen BS, Alves SE: Immunohistological study for estrogenic activities of nitrophenols in diesel exhaust particles. Endocrine Rev 1999, 20:279-307.

26. Watanabe N, Oonuki Y: Inhalation of diesel engine exhaust affects spermatogenesis in growing male rats. Environ Health Perspect 1999, 107:539-544.

27. Sugamata M, Ihara T, Takano H, Oshio S, Takeda K: Maternal diesel exhaust exposure damages newborn murine brains. J Health Sci 2006, 52:82-84.

28. Herlenius $E$, Lagercrantz $H$ : Development of neurotransmitter systems during critical periods. Exp Neurol 2004, 190(Suppl 1):S8-S21.

29. Kumagai Y, Arimoto T, Shinyashiki M, Shimojo N, Nakai Y, Yoshikawa T, Sagai M: Generation of reactive oxygen species during interaction of diesel exhaust particle components with NADPH-cytochrome P450 reductase and involvement of the bioactivation in the DNA damage. Free Radic Biol Med 1997, 22:479-487.

30. Semmler-Behnke M, Fertsch S, Schmid O, Wenk A, Kreyling WG: Uptake of $1.4 \mathrm{~nm}$ versus $18 \mathrm{~nm}$ gold nanoparticles in secondary target organs is size dependent in control and pregnant rats after intratracheal or intravenous application. Proceedings of the EuroNanoForum 2007: 19-21 June 2007; Düsseldorf European Communities 2007, 102-104.

31. Morgan MA, Pfaff DW: Effects of estrogen on activity and fear-related behaviors in mice. Horm Behav 2001, 40:472-482.

32. Morgan MA, Pfaff DW: Estrogen's effects on activity, anxiety, and fear in two mouse strains. Behav Brain Res 2002, 132:85-93.

33. Thierry AM, Tassin JP, Blanc G, Glowinski J: Selective activation of mesocortical DA system by stress. Nature 1976, 263:242-244.

34. Heffner TG, Heller A, Miller FE, Kotake C, Seiden LS: Locomotor hyperactivity in neonatal rats following electrolytic lesions of mesocortical dopamine neurons. Brain Res 1983, 285:29-37.

35. Oades RD, Taghzouti K, Rivet JM, Simon H, Le Moal M: Locomotor activity in relation to dopamine and noradrenaline in the nucleus accumbens, septal and frontal areas: a 6-hydroxydopamine study. Neuropsychobiology $1986,16: 37-42$

36. Kalsbeek A, de Bruin JP, Matthijssen MA, Uylings HB: Ontogeny of open field activity in rats after neonatal lesioning of the mesocortical dopaminergic projection. Behav Brain Res 1989, 32:115-127.

37. Abercrombie ED, Keefe KA, DiFrischia DS, Zigmond MJ: Differential effect of stress on in vivo dopamine release in striatum, nucleus accumbens, and medial frontal cortex. J Neurochem 1989, 52:1655-1658.

38. Cenci MA, Kalén P, Mandel RJ, Björklund A: Regional differences in the regulation of dopamine and noradrenaline release in medial frontal cortex, nucleus accumbens and caudate-putamen: a microdialysis study in the rat. Brain Res 1992, 581:217-228.

39. Imperato A, Puglisi-Allegra S, Casolini P, Angelucci L: Changes in brain dopamine and acetylcholine release during and following stress are independent of the pituitary-adrenocortical axis. Brain Res 1991, 538:111-117.

doi:10.1186/1743-8977-7-7

Cite this article as: Suzuki et al:: In utero exposure to a low concentration of diesel exhaust affects spontaneous locomotor activity and monoaminergic system in male mice. Particle and Fibre Toxicology 2010 7:7.

\section{Submit your next manuscript to BioMed Central and take full advantage of:}

- Convenient online submission

- Thorough peer review

- No space constraints or color figure charges

- Immediate publication on acceptance

- Inclusion in PubMed, CAS, Scopus and Google Scholar

- Research which is freely available for redistribution 